

\title{
Effects of bisphenol A on decreasing the percentage and promoting the growth of stem cell-like cells from $\mathrm{SK}-\mathrm{N}-\mathrm{SH}$ human neuroblastoma cells
}

\author{
J.C. Zheng ${ }^{1 *}$, S.Q. Qi' ${ }^{2 *}$, L. Yang ${ }^{1}$, Y.Y. Ma ${ }^{1}$, K.R. Dong ${ }^{1}$, H.T. Zhu ${ }^{1}$, \\ S.B. Yang ${ }^{1}$, T. Xu ${ }^{1}$, S. Zheng ${ }^{1}$ and X.M. Xiao ${ }^{1}$ \\ ${ }^{1}$ Department of Pediatric Surgery, Children's Hospital, Fudan University, \\ Shanghai, China \\ ${ }^{2}$ Department of Pediatric Surgery, Anhui Provincial Children's Hospital, \\ Hefei, China \\ *These authors contributed equally to this study. \\ Corresponding author: X.M. Xiao \\ E-mail: xxianmin@126.com
}

Genet. Mol. Res. 14 (2): 2986-2993 (2015)

Received February 18, 2014

Accepted December 12, 2014

Published April 10, 2015

DOI http://dx.doi.org/10.4238/2015.April.10.8

\begin{abstract}
Bisphenol A (BPA) is an industrial contaminant and is reported to be a risk factor associated with the development of tumors. In our previous studies, we have shown that BPA promoted the growth of SK-N-SH human neuroblastoma cells and increased their invasion and metastasis. In this study, we further investigated the effects of BPA and $17 \beta$-estradiol $\left(\mathrm{E}_{2}\right)$ on the stem cell-like cells from SK-N-SH cells. Detection of stem cell markers, proliferation assay, and clonogenic analysis showed that the side-population (SP) of SK-N-SH cells had properties similar to those of stem cells. BPA or $\mathrm{E}_{2}$ exposure decreased the percentage of SP cells and the expression of stem cell-marker proteins. BPA and $\mathrm{E}_{2}$ promoted the growth of non-SP cells to a greater extent than of SP cells; in addition, they significantly increased the
\end{abstract}


growth of SP cells. Thus, BPA has effects on stem cell-like cells, which induce tumor formation, and thus, BPA is an environmental factor that plays an important role in the development of neuroblastoma.

Key words: Neuroblastoma; Environmental estrogen; $17 \beta$-estradiol; Bisphenol A; Side population; SK-N-SH cells

\section{INTRODUCTION}

Environmental estrogen (EE) is a kind of an exogenous chemical that mimics and interferes with the effects of natural estrogen in the body (Markey et al., 2002; Mello-daSilva and Fruchtengarten, 2005). EE is ubiquitous in the environment, and thus, there have been growing concerns about the relationship between the EE and human health. Bisphenol A (BPA) is a well-known EE widely used in plastic products, including daily necessities such as food containers and medical devices such as blood storage bags (Markey et al., 2002). Accumulating evidence suggests that BPA is associated with reproductive disorders, cardiovascular diseases, abnormal liver function, and diabetes in human beings (Lang et al., 2008; vom Saal and Myers, 2008; Soto and Sonnenschein, 2010). Furthermore, many studies have shown that BPA influences the promotion or progression of many cancers such as seminoma, prostate cancer, and breast cancer (Bouskine et al., 2009; Hess-Wilson, 2009; LaPensee et al., 2010). In particular, children are vulnerable to EE exposure because they have a relatively large body surface area and limited catabolism (Mello-da-Silva and Fruchtengarten, 2005). Therefore, investigation of the relationship between BPA exposure and pediatric tumors is very important.

Neuroblastoma (NB) is a common childhood cancer that arises from the neural crest cells and accounts for $8-10 \%$ of childhood cancers (Mahller et al., 2009). Although most patients achieve remission with current treatment strategies, the ratio of long-term survival in high-risk patients continues to be less than 50\% (Suita et al., 2007). Therefore, studies on the risk factors and mechanisms involved in the development of NB are urgently required to improve the treatment for this poorly understood cancer. In our previous studies, we showed that BPA promotes the proliferation of SK-N-SH NB cells and improves their invasion and metastasis (Zheng et al., 2007; Zhu et al., 2009, 2010). Thus, we expect that BPA may play a role in the development of NB.

Many studies have shown that cancers contain a small subset of their own stem-like cells called cancer stem cells (CSCs) (Reya et al., 2001; Schatton et al., 2009). CSCs are thought to be the origin of tumor cells. CSCs may simultaneously have the characteristics of self-renewal, multipotency, and malignancy. Side population (SP) analysis is a classic method to isolate CSCs (Hadnagy et al., 2006). SP cells, the Hoechst 33342-negative cells sorted using flow cytometry (FCM), are enriched for CSCs. The SK-N-SH cells, which we used in our previous studies, also contain SP cells (Hirschmann-Jax et al., 2004; Mahller et al., 2009). Hirschmann et al. (2004) found that the SK-N-SH SP cells were multipotent and drug resistant; however, whether these cells were self-renewing and highly malignant remains unknown. Thus, to date, the SK-N-SH SP cells have not been thoroughly examined as a population of CSCs according to the three functional definitions of CSC. In this study, we examined the self-renewing ability and malignant potential of SK-N-SH SP cells, and then, investigated the effects of BPA on these cells. We believe that determining the effects of BPA on SK-N-SH SP cells will improve the understanding of the development of NB, and thus, enable the develop- 
ment of more effective therapies for NB patients who are refractory to conventional therapies.

\section{MATERIAL AND METHODS}

\section{Cell culture and treatment}

SK-N-SH human NB cells (obtained from Shanghai Institute for Biological Sciences, Chinese Academy of Sciences) and SK-N-SH subtype cells sorted by FCM were cultured in RPMI 1640 medium (Gibco, Scotland, UK) containing 10\% fetal bovine serum (FBS; Biochrom, Berlin, Germany), $100 \mathrm{U} / \mathrm{mL}$ penicillin, and $100 \mu \mathrm{g} / \mathrm{mL}$ streptomycin. Cells were incubated at $37^{\circ} \mathrm{C}$ in a humidified atmosphere with $5 \% \mathrm{CO}_{2}$. Before treatment with $20 \mu \mathrm{g} / \mathrm{mL}$ BPA (Shanghai Chemical Reagents Company, Shanghai, China) or $1 \mathrm{ng} / \mathrm{mL} 17 \beta$-estradiol ( $\mathrm{E}_{2}$; Sigma, St. Louis, MO, USA), the cells were seeded in phenol red-free RPMI 1640 medium (Sigma) supplemented with 10\% charcoal-dextran-stripped FBS (Gibco) for $48 \mathrm{~h}$ to exhaust the endogenous estrogen.

\section{FCM analysis and sorting of SP cells}

Exponentially growing cells were detached with $0.25 \%$ trypsin/0.02\% EDTA and suspended at $1 \times 10^{6}$ cells/mL in RPMI 1640 medium supplemented with $2 \% \mathrm{FBS}$, and then, stained with $5 \mu \mathrm{M}$ Hoechst 33342 (Sigma) in the presence or absence of $50 \mu \mathrm{mol} / \mathrm{L}$ verapamil (Sigma) at $37^{\circ} \mathrm{C}$ for $60 \mathrm{~min}$. Samples were washed, centrifuged, and resuspended in cold RPMI 1640 medium supplemented with $2 \%$ FBS, and then, $1 \mu \mathrm{g} / \mathrm{mL}$ propidium iodide (Sigma) was added. The FCM analysis and sorting of SP cells were performed using a BD FACSAria II flow cytometer (BD Biosciences, USA) as previously described (Komuro et al., 2007).

\section{Western blot analysis}

Cells were collected in standard sodium dodecyl sulfate (SDS) sample buffer. Protein concentrations were determined using the Bradford method, and protein extracts ( $20 \mu \mathrm{g} / \mathrm{lane})$ were separated on a $10 \%$ SDS-polyacrylamide gel, transferred to a nitrocellulose membrane, and probed with 1:200 anti-c-kit antibody (Santa Cruz Biotechnology, Inc., CA, USA), 1:1000 anti-ABCG2 antibody (Abcam Inc., Cambridge, MA, USA), or 1:1000 anti- $\beta$-actin antibody (Santa Cruz). Proteins were visualized using an enhanced chemiluminescence system (Amersham, UK) and were analyzed using the QualityOne Image Analysis software (Bio-Rad, Hercules, CA, USA). The experiments were repeated three times.

\section{Self-renewal assay}

Cells were grown on a 96-well plate at a density of $1 \times 10^{4}$ cells/well, and the relative cell number was determined using the Cell Counting Kit-8 (CCK-8; Dojindo, Kumamoto, Japan) according to the manufacturer protocol. Briefly, $10 \mu \mathrm{L}$ CCK-8 dye was added to each well and the plate was incubated for $2 \mathrm{~h}$ at $37^{\circ} \mathrm{C}$. The absorbance value (AV) was measured at $450 \mathrm{~nm}$ using a microplate reader (Model 680; Bio-Rad). The experimental wells were analyzed in quintuplicate, and the whole experiment was repeated three times. 


\section{Clonogenic analysis}

Cells were cultured on $3.5-\mathrm{cm}$ plates at 1000 cells/plate in RPMI 1640 containing $15 \%$ FBS. Fresh medium was supplemented once in 3 days. Clones with $>50$ cells were counted after 14 days. The percentage of cells that developed a clone was described as cloning efficiency $(\%)$. The experiments were performed in triplicate.

\section{Statistical analysis}

Data are reported as means \pm standard error of mean (SE) and analyzed by the SPSS 13.0 software (SPSS Inc., Chicago, IL, USA). The Student $t$-test and repeated design analysis of variance were used for comparison between groups. $\mathrm{P}<0.05$ was considered to be significant.

\section{RESULTS}

\section{SK-N-SH SP cells possess several CSC-like properties}

Our previous studies showed that the SK-N-SH SP cells have CSC-like properties (Qi et al., 2010). To study the effects of BPA and $E_{2}$ on SP cells, we first sorted SP and non-SP (NSP) cells from the SK-N-SH cell line, and then, analyzed their relative characteristics such as expression of stem cell-marker proteins, ability of self-renewal, and ability of clone formation. SP cells were sorted as described previously (Qi et al., 2010), and they accounted for 3.6 $\pm 0.2 \%$ of the total cells. C-kit is a marker for the neural crest stem cells (Cui et al., 2006). Freshly sorted SP cells expressed higher levels of c-kit protein than freshly sorted NSP cells $(\mathrm{P}<0.01$; Figure 1A). The average AVs for SP and NSP cells were $0.242 \pm 0.017$ and $0.248 \pm$ 0.017 , respectively, on day 2 after sorting $(\mathrm{P}>0.05), 0.898 \pm 0.041$ and $0.349 \pm 0.025$ on day $5(\mathrm{P}<0.01)$, and $1.199 \pm 0.154$ and $0.647 \pm 0.055$ on day $7(\mathrm{P}<0.01$; Figure $1 \mathrm{~B})$. The number of colonies was $187 \pm 23(18.7 \%)$ in the parental cells and $578 \pm 23(57.8 \%)$ in the SP cells (P $<0.01$; Figure 1C and Figure S1A). We observed only few aggregates among the 3000 NSP cells in the experiments repeated thrice, which accounted for $<50$ cells (Figure S1). Thus, the number of colonies was $0(0 \%)$ in the NSP cells ( Figure S1B $)$.
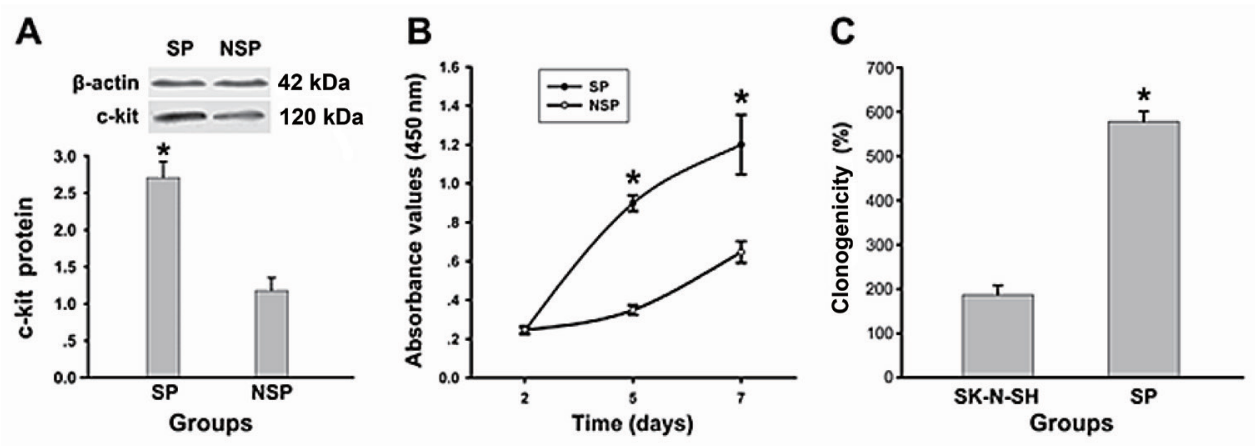

Figure 1. Analysis of the stem cell-like properties of side population (SP) cells. Immunoblot analysis of c-kit in freshly sorted SP and non-SP (NSP) cells (A). The CCK-8 assay was performed at the indicated time points to quantify the number of viable SP and NSP cells $(\mathbf{B})$. Clonogenic ability of SP and NSP cells $(\mathbf{C}) . * \mathrm{P}<0.01$. 


\section{BPA or $E_{2}$ exposure decreases the percentage of SP cells}

The percentage of SP cells was $2.6 \pm 0.3 \%, 1.5 \pm 0.1 \%$, and nearly zero after treatment of SK-N-SH cells with BPA for 2, 5, and 7 days, respectively (Figure 2A and Figure S2). The percentage of SP cells was $2.7 \pm 0.2 \%, 1.6 \pm 0.5 \%$, and nearly zero after treatment of SK-NSH cells with $\mathrm{E}_{2}$ for 2, 5, and 7 days, respectively (Figure 2B and Figure S3).

A

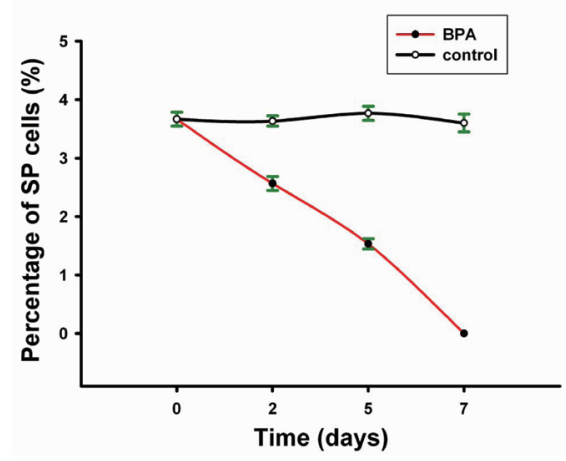

B

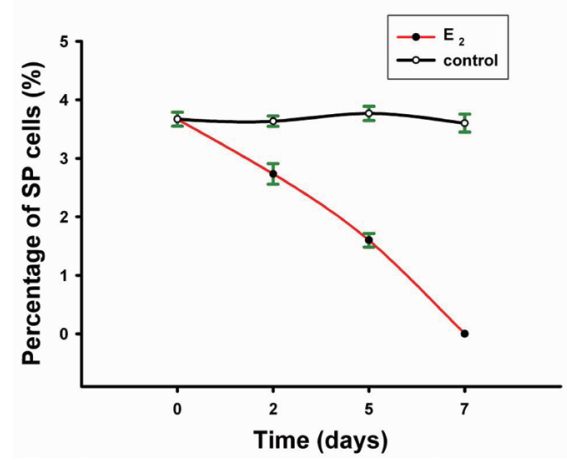

Figure 2. Percentage of side population (SP) cells decreased after treatment with bisphenol A (BPA) (A) and $17 \beta$-estradiol $\left(\mathrm{E}_{2}\right)(\mathbf{B})$ for the indicated time points.

\section{BPA or $E_{2}$ exposure reduces the expression of c-kit and ABCG2 proteins}

After 7 days of exposure, BPA reduced the expression of c-kit and ABCG2 proteins $(\mathrm{P}<0.05$ and $\mathrm{P}<0.01$, respectively, compared to black control, Figure $3 \mathrm{~A}$ and $\mathrm{C})$; in addition, $\mathrm{E}_{2}$ decreased the expression of c-kit and $\mathrm{ABCG} 2$ proteins $(\mathrm{P}>0.05$ and $\mathrm{P}<0.05$, respectively, compared to black control, Figure 3B and D).

A
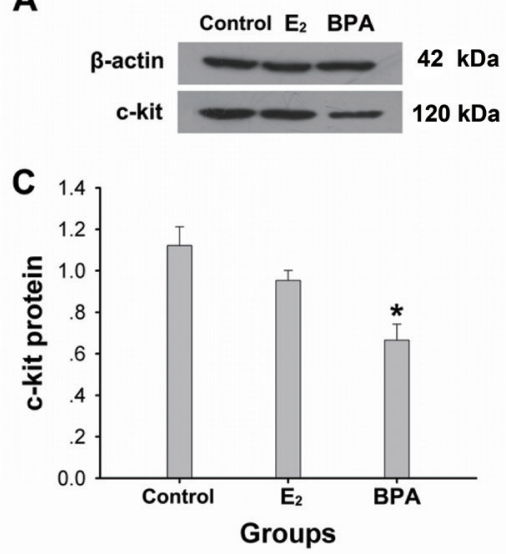

B
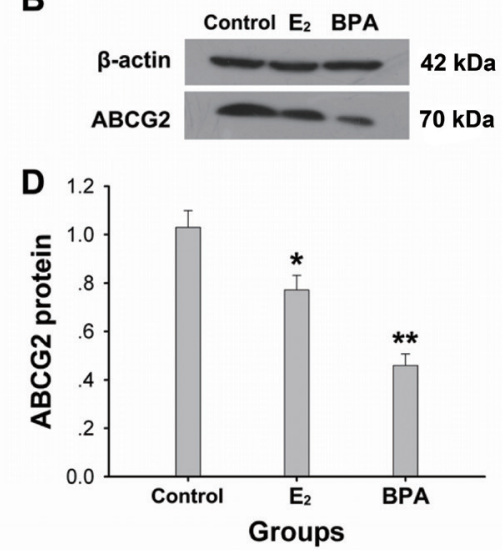

Figure 3. Immunoblot analysis of c-kit (A) and ABCG2 (B) in SK-N-SH cells 7 days after exposure to bisphenol $\mathrm{A}(\mathrm{BPA})$ and $17 \beta$-estradiol $\left(\mathrm{E}_{2}\right)$. Compared to control, $* \mathrm{P}<0.05, * * \mathrm{P}<0.01$. 


\section{BPA and $E_{2}$ promote the growth of NSP cells to a significantly greater extent than that of SP cells}

The average AV of SP and NSP cells on day 5 after BPA exposure was $1.5644 \pm 0.0446$ $(\mathrm{P}<0.05$, vs blank control, $1.2516 \pm 0.0669$, Figure 4A) and $1.1448 \pm 0.06181(\mathrm{P}<0.01, v s$ blank control, $0.6793 \pm 0.0245$, Figure 4A), respectively. Thus, BPA promoted the growth of NSP cells to a significantly greater extent than that of SP cells $(69 v s 25 \%, \mathrm{P}<0.01$, Figure $4 \mathrm{~A})$. The average AV of SP and NSP cells on day 5 after $\mathrm{E}_{2}$ exposure was $1.5643 \pm 0.0401$ ( $\mathrm{P}$ $<0.05$, vs blank control, $1.2516 \pm 0.0669$, Figure 4B) and $1.1061 \pm 0.0617(\mathrm{P}<0.01$, vs blank control, $0.6793 \pm 0.0245$, Figure 4B), respectively. $\mathrm{E}_{2}$ promoted the growth of NSP cells to a significantly greater extent than that of SP cells ( $63 v s 25 \%, \mathrm{P}<0.05$, Figure 4B).

A

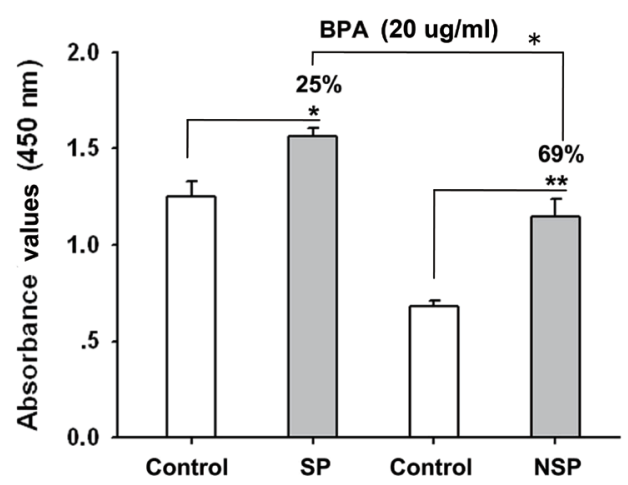

B

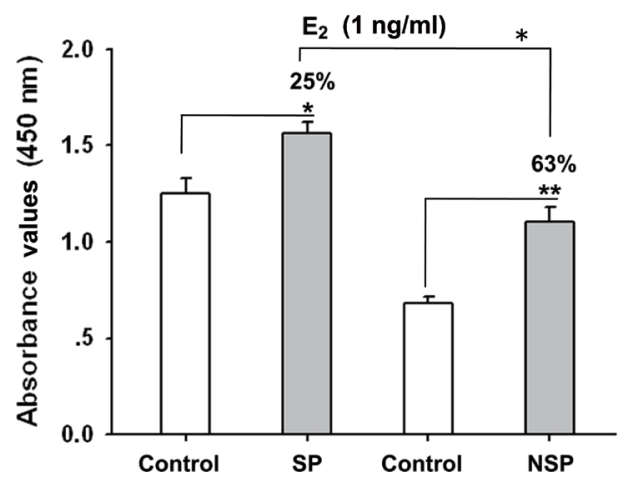

Figure 4. Proliferative analysis of side population (SP) and non-SP (NSP) cells using the CCK- 8 assay 5 days after exposure to $20 \mu \mathrm{g} / \mathrm{mL}$ bisphenol A (BPA) (A) and $1 \mathrm{ng} / \mathrm{mL} 17 \beta$-estradiol ( $\left.\mathrm{E}_{2}\right)(\mathbf{B})$. $* \mathrm{P}<0.05,{ }^{*} \mathrm{P}<0.01$.

\section{DISCUSSION}

The SK-N-SH cell line, obtained from a 4-year-old girl with bone marrow metastasis, is a poorly differentiated NB cell line and is often used as a representative to elucidate the characteristics of NB (Biedler et al., 1973). Our previous studies showed that SK-N-SH cells express $\beta$-estrogen receptor (ER), and BPA mimics the function of the endogenous estrogen to promote their growth, improves their invasion and metastasis by an ER-dependent pathway (Zheng et al., 2007; Zhu et al., 2009, 2010). To efficiently analyze the effects of BPA on SP cells, we used $\mathrm{E}_{2}$, one of the most important estrogens, as a control in our experiments. The concentration of BPA used in this study is similar to the concentration present in the environment (Fromme et al., 2002; Stachel et al., 2003) and is used commonly in experimental studies (Hanet et al., 2008; Huang and Leung, 2009). Our preliminary experiments confirmed that the effects of $1 \mathrm{ng} / \mathrm{mL} \mathrm{E}_{2}$ and $20 \mu \mathrm{g} / \mathrm{mL}$ BPA had similar effects on SK-N-SH cells.

CSCs express high levels of CSC-specific molecular markers (Mahller et al., 2009). SK-N-SH SP cells express high levels of the stem cell marker protein c-kit, which implies that they possess the characteristics of CSCs at the protein level. Comparison of the speed of proliferation can be used to identify the self-renewal ability of different cell lines (Wan et 
al., 2010). The SK-N-SH SP cells proliferate faster than NSP cells, which indicates that the $\mathrm{SP}$ cells have a high self-renewal ability. Clonogenic ability is proportional to the malignant potential of cells (Shi et al., 2008); therefore, the high clonogenic ability of SK-N-SH SP cells observed in this study indicates that these cells are highly malignant. Hirschmann-Jax et al. (2004) found that SK-N-SH SP cells were multipotent, while our results showed that the SP cells were self-renewing and highly malignant. These findings suggest that SK-N-SH SP cells have several characteristics similar to those of CSCs.

Similar to $\mathrm{E}_{2}$, BPA treatment decreased the percentage of SP cells to nearly zero and reduced the expression of stem cell-marker proteins. ABCG2 contributes to the exclusion of Hoechst in SP cells (Komuro et al., 2007) and can be a stem cell marker (Ding et al., 2010). Therefore, decrease in ABCG2 expression is consistent with the decrease in the percentage of SP cells. Our previous studies showed that BPA promoted the growth, invasion, and metastasis of SK-N-SH cells; thus, we anticipated that BPA may increase the percentage of SP cells and upregulate the expression of stem cell markers; however, we obtained results contrary to our expectations. Our findings may be explained as follows: although BPA promotes the growth of SP and NSP cells, it accelerates the growth of NSP cells more significantly than that of SP cells, and thus, the percentage of SP cells and the expression of stem cell marker ABCG2 are decreased because of the rapid increase in the number of NSP cells. Another interesting question that needs to be addressed is why NSP cells proliferate much faster than SP cells when exposed to BPA. SP cells are drug resistant (Hirschmann-Jax et al., 2004), and thus, they survive after exposure to chemotherapeutic drugs and possibly resist the proliferation-promoting drugs such as BPA, which may explain the lower growth rate of SP cells than of NSP cells.

Although BPA decreases the percentage of SP cells and reduces the expression of stem cell-marker proteins, it exhibits significant growth-promoting effects on SP cells. As a population of enriched CSCs, SP cells are believed to contribute to the development of tumor, and our results indicate that BPA is an environmental factor that may promote the genesis of NB.

In summary, the SK-N-SH SP cells have the characteristics of CSCs, and BPA promotes the growth of SK-N-SH SP cells, which indicates that BPA is a hazardous environmental factor that may play a role in promoting the development of NB.

\section{ACKNOWLEDGMENTS}

We thank Dr. Xiaoping Liu for his expertise in flow cytometry. Research supported by the National Natural Science Foundation Commission (\#30801198), the Doctoral Fund of Ministry of Education of China and the Youth Scientific Research Foundation of Shanghai (youth \#2007-QN-74).

\section{Supplementary material}

\section{REFERENCES}

Biedler JL, Helson L and Spengler BA (1973). Morphology and growth, tumorigenicity, and cytogenetics of human neuroblastoma cells in continuous culture. Cancer Res. 33: 2643-2652.

Bouskine A, Nebout M, Brucker-Davis F, Benahmed M, et al. (2009). Low doses of bisphenol A promote human seminoma cell proliferation by activating PKA and PKG via a membrane G-protein-coupled estrogen receptor. Environ. Health Perspect. 117: 1053-1058.

Cui H, Ma J, Ding J, Li T, et al. (2006). Bmi-1 regulates the differentiation and clonogenic self-renewal of I-type 
neuroblastoma cells in a concentration-dependent manner. J. Biol. Chem. 281: 34696-34704.

Ding XW, Wu JH and Jiang CP (2010). ABCG2: a potential marker of stem cells and novel target in stem cell and cancer therapy. Life Sci. 86: 631-637.

Fromme H, Kuchler T, Otto T, Pilz K, et al. (2002). Occurrence of phthalates and bisphenol A and F in the environment. Water Res. 36: 1429-1438.

Hadnagy A, Gaboury L, Beaulieu R and Balicki D (2006). SP analysis may be used to identify cancer stem cell populations. Exp. Cell Res. 312: 3701-3710.

Hanet N, Lancon A, Delmas D, Jannin B, et al. (2008). Effects of endocrine disruptors on genes associated with 17betaestradiol metabolism and excretion. Steroids 73: 1242-1251.

Hess-Wilson JK (2009). Bisphenol A may reduce the efficacy of androgen deprivation therapy in prostate cancer. Cancer Causes Control 20: 1029-1037.

Hirschmann-Jax C, Foster AE, Wulf GG, Nuchtern JG, et al. (2004). A distinct "side population" of cells with high drug efflux capacity in human tumor cells. Proc. Natl. Acad. Sci. U. S. A. 101: 14228-14233.

Huang H and Leung LK (2009). Bisphenol A downregulates CYP19 transcription in JEG-3 cells. Toxicol. Lett. 189: 248252.

Komuro H, Saihara R, Shinya M, Takita J, et al. (2007). Identification of side population cells (stem-like cell population) in pediatric solid tumor cell lines. J. Pediatr. Surg. 42: 2040-2045.

Lang IA, Galloway TS, Scarlett A, Henley WE, et al. (2008). Association of urinary bisphenol A concentration with medical disorders and laboratory abnormalities in adults. JAMA 300: 1303-1310.

LaPensee EW, LaPensee CR, Fox S, Schwemberger S, et al. (2010). Bisphenol A and estradiol are equipotent in antagonizing cisplatin-induced cytotoxicity in breast cancer cells. Cancer Lett. 290: 167-173.

Mahller YY, Williams JP, Baird WH, Mitton B, et al. (2009). Neuroblastoma cell lines contain pluripotent tumor initiating cells that are susceptible to a targeted oncolytic virus. PLoS One 4: e4235.

Markey CM, Rubin BS, Soto AM and Sonnenschein C (2002). Endocrine disruptors: from Wingspread to environmental developmental biology. J. Steroid Biochem. Mol. Biol. 83: 235-244.

Mello-da-Silva CA and Fruchtengarten L (2005). Environmental chemical hazards and child health. J. Pediatr. 81: S205-S211.

Qi S, Zheng J, Zhu H, Yang L, et al. (2010). Identification of neuroblastoma stem cells by characterization of side population cells in the human neuroblastoma SK-N-SH cell line. J. Pediatr. Surg. 45: 2305-2311.

Reya T, Morrison SJ, Clarke MF and Weissman IL (2001). Stem cells, cancer, and cancer stem cells. Nature 414: 105-111. Schatton T, Frank NY and Frank MH (2009). Identification and targeting of cancer stem cells. Bioessays 31: 1038-1049.

Shi GM, Xu Y, Fan J, Zhou J, et al. (2008). Identification of side population cells in human hepatocellular carcinoma cell lines with stepwise metastatic potentials. J. Cancer Res. Clin. Oncol. 134: 1155-1163.

Soto AM and Sonnenschein C (2010). Environmental causes of cancer: endocrine disruptors as carcinogens. Nat. Rev. Endocrinol. 6: 363-370.

Stachel B, Ehrhorn U, Heemken OP, Lepom P, et al. (2003). Xenoestrogens in the River Elbe and its tributaries. Environ. Pollut. 124: 497-507.

Suita S, Tajiri T, Kaneko M, Hirai M, et al. (2007). Implications of MYCN amplification in patients with stage 4 neuroblastoma who undergo intensive chemotherapy. J. Pediatr. Surg. 42: 489-493.

vom Saal FS and Myers JP (2008). Bisphenol A and risk of metabolic disorders. JAMA 300: 1353-1355.

Wan G, Zhou L, Xie M and Chen H (2010). Characterization of side population cells from laryngeal cancer cell lines. Head Neck 32: 1302-1309.

Zheng J, Xiao X, Liu J, Zheng S, et al. (2007). Growth-promoting effect of environmental endocrine disruptors on human neuroblastoma SK-N-SH cells. Environ. Toxicol. Pharmacol. 24: 189-193.

Zhu H, Xiao X, Zheng J, Zheng S, et al. (2009). Growth-promoting effect of bisphenol A on neuroblastoma in vitro and in vivo. J. Pediatr. Surg. 44: 672-680.

Zhu H, Zheng J, Xiao X, Zheng S, et al. (2010). Environmental endocrine disruptors promote invasion and metastasis of SK-N-SH human neuroblastoma cells. Oncol. Rep. 23: 129-139. 